\title{
Justiça racial e direitos humanos dos povos e comunidades tradicionais
}

\author{
Daiane de Oliveiva Gomes ${ }^{1}$ \\ https://orcid.org/0000-0002-6294-2816
}

\author{
Wanessa Nhayara Maria Pereira Brandão ${ }^{3}$ \\ https://orcid.org/0000-0002-1039-9276
}

\author{
Maria Zelma de Araújo Madeira ${ }^{2}$ \\ https://orcid.org/0000-0003-2291-4455

\begin{abstract}
${ }^{1}$ Instituto Federal de Educação, Ciência e Tecnologia da Paraíba, Diretoria de Desenvolvimento de Ensino, Coordenação de Apoio aos Estudantes, Cajazeiras, PB, Brasil

${ }^{2}$ Universidade Estadual do Ceará, Centro de Estudos Sociais Aplicados, Programa de Pós Graduação em Serviço Social, Trabalho e Questão Social, Fortaleza, CE, Brasil

${ }^{3}$ Universidade Estadual do Ceará, Centro de Estudos Sociais Aplicadas, Programa de Pós Graduação em Serviço Social, Trabalho e
\end{abstract} \\ Questão Social, Fortaleza, CE, Brasil
}

\begin{abstract}
Justiça racial e direitos humanos dos povos e comunidades tradicionais
Resumo: O objetivo deste artigo é contextualizar o cenário atual de crescimento do autoritarismo, de ataques aos direitos humanos e à democracia, tendo como eixo analítico e político a categoria raça. Interessa compreender a questão racial nas agendas das políticas públicas e dos direitos humanos dos povos e comunidades tradicionais, em particular os indígenas e quilombolas e os efeitos perversos do projeto de colonialidade. Conclui-se que a herança e a recriação da escravidão e o racismo estrutural estão fortalecidos em um contexto em que se proliferam discursos e práticas públicas de ódio e outras formas de intolerância. Em paralelo, a agenda dos direitos humanos e das políticas públicas segue reproduzindo o silenciamento e a morosidade quando se trata da pauta das desigualdades e subordinações raciais.
\end{abstract}

Palavras-chave: Direitos humanos. Justiça racial. Povos e comunidades tradicionais.

\section{Racial justice and human rights of traditional peoples and communities}

Abstract: The objective of this article is to contextualize the current scenario of growth of authoritarianism and of attacks on human rights and democracy, using race as an analytical and political axis. It is interesting to understand the issue of race in the agendas of public policies and human rights of traditional peoples and communities, in particular with the indigenous and quilombolas, and the perverse effects of the colonial project. We conclude that the legacy and recreation of slavery and structural racism are strengthened in a context in which hate speech, hateful public practices, and other forms of intolerance proliferate. In parallel, the human rights and public policy agenda continues to reproduce silence and slowness when it comes to dealing with the agenda of racial inequality and subordination. Keywords: Human rights. Racial justice. Traditional peoples and communities.

Recebido em 04.11.2019. Aprovado em 11.02.2020. Revisado em 26.03.2020

(C) O(s) Autor(es). 2020 Acesso Aberto Esta obra está licenciada sob os termos da Licença Creative Commons Atribuição-NãoComercial 4.0 Internacional (https://creativecommons.org/licenses/by-nc/4.0/deed.pt_BR), que permite copiar, distribuir e reproduzir em qualquer meio, bem como adaptar, transformar e criar a partir deste material, desde que para fins não comerciais e que você forneça o devido crédito aos autores e a fonte, insira um link para a Licença Creative Commons e indique se mudanças foram feitas. 


\section{Introdução}

O Brasil é um país marcado pela diversidade cultural e étnica - contudo, tal riqueza tem sido subsumida sob o manto do silenciamento acerca da questão racial. Campeão em desigualdades, as desvantagens são profundamente presentes na realidade da população negra e de segmentos dos povos e comunidades tradicionais que vivem e sobrevivem em condições sociais desiguais e racialmente seletivas.

Predomina no País a naturalização das hierarquias raciais. O projeto de colonialidade, a escravidão moderna e seus efeitos perversos sob a forma do racismo estrutural prevalecem. Logo, é revisitando nosso passado cruel de exploração e discriminação que desvendamos a forma como a categoria raça serviu para instituir uma linha que separa de forma contundente grupos socialmente incluídos e outros oprimidos e fortemente subalternizados. Na esteira dessa compreensão, Pires (2018) assinala, à luz do pensamento de Frantz Fanon, o quanto é relevante trabalhar analítica e politicamente com a categoria raça.

O projeto moderno/colonial mobilizou a categoria raça para instituir uma linha que separa de forma incomensurável duas zonas: a do humano (zona do ser) e a do não humano (zona do não ser). Sendo o padrão de humanidade determinado pelo sujeito soberano (homem, branco, cis/hétero, cristão, proprietário e sem deficiência), também ele definirá o sujeito de direito a partir do qual se construirá toda narrativa jurídica (PIRES, 2018, p. 66).

Encontram-se na zona do não ser os sujeitos dos quais tratará este artigo, Povos e Comunidades Tradicionais $^{1}$ que convivem cotidianamente com a violência, com a violação de direitos e tendo de vencer muitos obstáculos para ter ativados os processos de proteção e promoção de direitos humanos.

Nesse sentido, é importante compreender o aumento do autoritarismo e seus impactos sobre a democracia e os direitos humanos. Tem destaque a retórica nacionalista que recorre ao discurso de ódio contra as minorias raciais. O populismo nacionalista de direita em todo o mundo desencadeou de forma franca e aberta discursos e práticas públicas de racismo, xenofobia, misoginia e outras formas de intolerância.

No tempo presente, prolifera o populismo autoritário, abalando a recente democracia instaurada no Brasil. Assim, são elucidativas as palavras de Schwarcz (2019) sobre as estratégias comuns dos governos para abalar as bases institucionais das democracias no mundo:

[...] a seleção de um passado mítico e glorioso; a criação de um anti-intelectualismo e um antijornalismo de base; um retorno à sociedade patriarcal de maneira a elevar conceitos como hierarquias e ordem; o uso da política do Estado ou, se necessário, de milícias para reprimir bandidos mas também desafetos políticos; uma verdadeira histeria sexual que acusa mulheres, gays, travestis e outras minorias de serem responsáveis pela degeneração moral de suas nações; um apelo à própria vitimização (a sua e de seus aliados), conclamando a população a reagir aos supostos algozes de outrora; o incentivo à polarização que divide a população entre "eles" e "nós", estabelecendo que "nós" somos os realizadores e "eles" os usurpadores; o uso extensivo da propaganda política que não preza a realidade pois prefere inventá-la; a naturalização de certos grupos nacionais e a consequente ojeriza aos imigrantes, logo transformados em estrangeiros; a manipulação do Estado, de suas instituições e leis, visando perpetuar o controle da máquina e garantir um retorno nostálgico aos valores da terra, da família e das tradições, como se esses fossem sentimentos puros, imutáveis e resguardados (SCHWARCZ, 2019, p. 226-227).

Essas narrativas autoritárias têm sido utilizadas para acirrar ainda mais preconceitos, discriminações raciais e a prática do racismo contra os povos e comunidades tradicionais, diminuindo as oportunidades de eles acessarem direitos, terem sua história respeitada e reconhecimento étnico ativado.

O Brasil parecia aberto ao século XXI com um sistema político democrático novo mais fortalecido, porém alguma coisa deixou de funcionar entre 2015 e 2017 - mudanças que colocaram em dúvida a qualidade de nossa democracia.

Naquele momento, e hoje também, a República no Brasil falha na disposição de garantir direitos, em especial direitos civis, com manifestações de racismo, diversos gestos de homofobia, feminicídio, falta de políticas dirigidas às pessoas com deficiências de toda ordem, ataques aos povos indígenas e a seus direitos à terra, assim como aqueles destinados aos quilombolas (SCHWARCZ; STARLING, 2018, p. 5).

Nossa diversidade populacional nos leva necessariamente a analisar os grupos étnicos, aqueles posicionados socialmente como representativos da zona do não ser - como população negra, povos originários, 
pescadores artesanais, populações atingidas por barragens, povos de terreiros, povos ciganos, dentre outros. Cabe a nós compreendermos os impactos dos atuais retrocessos para a realidade dessas populações, no seu modo de viver e no acesso às políticas públicas, bem como suas formas de resistir e as suas propostas para a consolidação de outra forma de desenvolvimento.

Em meio a um contexto econômico, social e político em que se proliferam e aprofundam, em nível de barbárie, discursos e práticas públicas de racismo, xenofobia, misoginia e outras formas de intolerância, as reivindicações desses grupos discriminados em termos étnicos e raciais são deslegitimadas. Cabe a nós denunciar a negligência nas agendas das políticas públicas e na agenda dos direitos humanos em alcançar o cerne da questão racial.

\section{Ausência da questão racial nas agendas das políticas públicas e dos direitos humanos}

Uma análise fecunda sobre as políticas públicas e efetivação dos direitos socioassistenciais em contexto de restrição fiscal deve considerar central a perspectiva de justiça racial, pela ênfase no racismo estrutural, sem tirar o foco da desigualdade econômica - que deve ser entendida como reflexo da profunda desigualdade nas estruturas de poder subjacentes que governam as sociedades. Daí ter valia a abordagem interseccional para a promoção da igualdade racial.

Raça é um elemento estruturante de como os direitos foram e são concebidos, negados e usufruídos de forma desigual no Brasil - e em todo o mundo. Para Silvio de Almeida (2018, p. 25), o racismo é um sistema estrutural, pois "[...] é uma forma sistemática de discriminação que tem a raça como fundamento, e que se manifesta por meio de práticas conscientes ou inconscientes que culminam em desvantagens ou privilégios para indivíduos, a depender do grupo racial ao qual pertençam".

Para acabar com o racismo, devemos mencionar raça explicitamente, priorizar uma abordagem interseccional e estrutural para a discriminação racial e levar a sério o papel das comunidades de cor e seus representantes, não só na luta contra a desigualdade racial, mas também na definição da natureza dos direitos humanos.

Raça, gênero e classe social estruturam opressões que se combinam e se entrecruzam, retraduzindo falhas na disposição de garantia de direitos. Partimos assim de uma perspectiva comprometida com os atravessamentos entre raça, classe, gênero, sexualidade e capacidade como estruturais e estruturantes de relações intersubjetivas e institucionais, e não somente atributos identitários.

O racismo não é um "problema" da ordem do privado: o racismo é um problema de ordem pública, cujo combate passa pela responsabilidade das instituições políticas. "Objetificados, desumanizados, infantilizados, docilizados, muitas são as expressões que denunciam o tratamento conferido aos que estão na zona do não ser pelo projeto moderno colonial escravista e por formas atualizadas de desres-

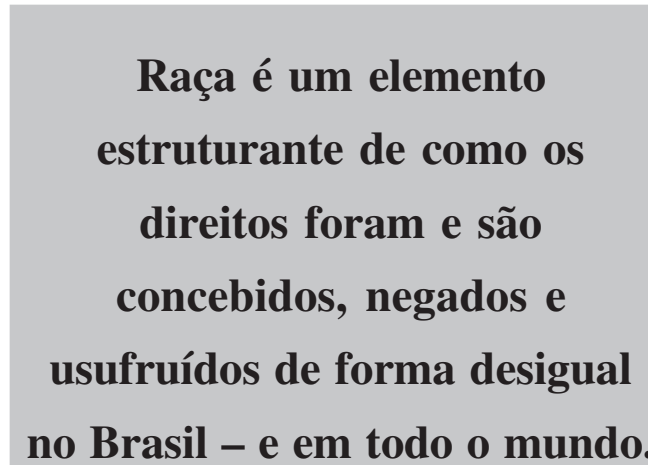
peito e extermínio" (PIRES, 2018, p. 67).

Considerando o enraizamento do racismo nos fundamentos das relações sociais brasileiras, cabe questionarmos: as políticas sociais setoriais e de direitos humanos combatem a sério as estruturas historicamente arraigadas de opressão racial, exploração e exclusão que violam os direitos humanos de muita gente?

Para Theodoro (2013), após décadas de negação da existência do racismo, com seu reconhecimento passamos à situação de uma difícil consolidação da temática da desigualdade racial como objeto legítimo e necessário da intervenção pública. Para o autor, a concretização da questão racial como campo de intervenção política, no Brasil, ainda está por ser concluída. "Até hoje, uma parcela ainda significativa da população não vê importância ou necessidade de Políticas de Promoção da Igualdade Racial. O racismo em sua teia onipresente impõe grandes obstáculos à consolidação de uma instância governamental de combate ao próprio racismo" (THEODORO, 2013, p. 5).

De acordo com o autor, a atuação do Movimento Negro foi crucial para a abertura de espaço para o debate da questão racial no país. Em fins da década de 1970, no decorrer do processo de democratização, o combate ao racismo assume importante posição no palco das lutas políticas; contudo,

[a] bandeira da igualdade racial, no entanto, não foi plenamente assumida pelos demais segmentos organizados da sociedade brasileira. Permaneceu quase exclusivamente como tema do movimento negro, pois sua 
incorporação ao espectro das lutas sociais não se deu por completo. A temática racial, em verdade, nunca chegou a se constituir em uma questão nacional, e não foi assumida como prioridade entre as esquerdas, mesmo as mais democráticas (THEODORO, 2013, p. 6).

Apesar disso, o Movimento Negro foi firme em suas denúncias da vigência do racismo como ideologia ativa e da discriminação como prática social sistemática. Junto a isso, as análises sobre as desigualdades raciais no país se intensificaram, ratificando o entendimento acerca das particularidades do racismo no Brasil e suas consequências. Assim, o tema das desigualdades raciais ganhou destaque no país no cerne da discussão sobre a questão social. Ao redor de toda essa problemática, foram apresentadas demandas de enfrentamento ao racismo e às desigualdades sociais.

Vale destacar que a consolidação da temática racial estrutural para a formação da desigualdade social brasileira se deu e se dá de forma não linear, com fortes contestações, inflexões e esbarrando em vários entraves.

Jaccoud (2008) elucida que, entre as décadas de 1980 e 2000, as iniciativas no campo da atuação governamental voltadas à promoção da igualdade racial se ampliaram e se alteraram significativamente. Apesar disso, foram em sua maioria experiências pontuais e superficiais em seus impactos. Essas ações implementadas estiveram (e continuam) desarticuladas entre si, assim como de algum objetivo concreto de redução das desigualdades raciais. Do mesmo modo, não se apresentavam institucionalmente na forma de programas, com metas fixadas e escalonadas ao longo do tempo, planejamento de ações ou orçamento.

No decorrer dos governos do Partido dos Trabalhadores, foi sendo consolidado um aparato institucional com o objetivo de implementar a Política de Promoção da Igualdade Racial, que apresentou avanços relevantes. Dentre esses, a criação da Secretaria Especial de Políticas de Promoção da Igualdade Racial (Seppir), em 2003, que foi seguida da criação de vários órgãos de mesma natureza em nível estadual; no campo das legislações, destaca-se a criação do Estatuto da Igualdade Racial²; e, como instância de controle social, a criação do Conselho Nacional de Promoção da Igualdade Racial.

Contudo, as ações governamentais não se consolidaram como um conjunto de programas e ações compatíveis, em dimensão e quantidade de recursos, com a importância da questão racial no Brasil. Por sua vez, a partir de 2015, o aparato institucional e legislativo construído no decorrer das últimas décadas vem passando por forte ataque e desmantelamento.

O contexto iniciado a partir do impeachment da presidente da República Dilma Rousseff - materializado por meio de um golpe de Estado jurídico parlamentar que destituiu a presidenta e empossou o então vicepresidente Michel Temer - foi definidor para o aprofundamento de ações de desmonte das políticas sociais e subtração de direitos sociais.

Como exemplo, podemos citar a Ementa Constitucional n 95, de 2016, que prevê o congelamento dos gastos públicos de 2017 a 2036. Com a redução dos gastos federais nas políticas sociais, os direitos sociais e a proteção social são enfraquecidos, e a participação social, fragilizada. Tais medidas inviabilizam sistemas públicos estatais e a democracia no Brasil. Por sua vez, afetam mais profundamente a população mais pobre e em condição mais desigual por questões de classe, gênero e étnico-racial. Junto a isso, o atual líder do cargo político de mais alto nível no País professa abertamente concepções racistas e xenofóbicas, ao mesmo tempo em que adota políticas que as consolidam.

As políticas públicas especificamente voltadas aos povos e comunidades tradicionais se interligam às políticas públicas direcionadas à promoção da igualdade racial. Como exemplos de algumas das principais ações constituídas, podemos citar: a educação escolar indígena e quilombola, integrante das Diretrizes Curriculares Nacionais e com pedagogia própria, considerando as especificidades desses povos; a Política Nacional de Atenção à Saúde dos Povos Indígenas ${ }^{4}$, integrante da Política Nacional de Saúde e praticada no âmbito do Sistema Único de Saúde (SUS) por meio do Departamento de Saúde Indígena (Desai); o Programa Brasil Quilombola (PBQ), objetivando, entre outros, a garantia do acesso à terra, à saúde e à educação, bem como construção de moradias, eletrificação, recuperação ambiental, incentivo ao desenvolvimento local e medidas de preservação e promoção das manifestações culturais dessas comunidades; as políticas fundiárias específicas para a delimitação e o reconhecimento de terras quilombolas e indígenas.

Contudo, com o início do atual governo, acentua-se o poder das corporações e do agronegócio, o que abre caminho para um ataque direto à política ambiental e aos direitos dos povos originários e comunidades tradicionais. A fragilização dos sistemas de proteção social e das políticas públicas que compõem o Plano Nacional de Segurança Alimentar e Nutricional (Plansan) e o Plano Nacional de Agroecologia, sobretudo os destinados à agricultura familiar e camponesa, povos indígenas e aos povos e comunidades tradicionais (PCTs), também têm tido forte impacto sobre a condição de vida de indígenas e quilombolas.

Para além da implementação das políticas setoriais e políticas específicas de promoção da igualdade racial para povos e comunidades tradicionais, as abordagens formais da questão racial, mesmo na agenda dos 
direitos humanos, não conseguem alavancar a promessa da Convenção Internacional sobre a Eliminação da Discriminação Racial (Icerd) e da Convenção no 169 da Organização Internacional do Trabalho.

Achiume (2018) aponta a tendência mais geral de negligência no que se refere à pauta racial de atores não governamentais e multilaterais com influência global que detêm o poder na produção de conhecimento e na definição da agenda dos direitos humanos.

\begin{abstract}
Embora atores influentes dentro do sistema global de direitos humanos tenham soado o alarme contra expressões ou atos viscerais de racismo e xenofobia, eles não combatem a sério as estruturas historicamente arraigadas de opressão racial, exploração e exclusão que violam os direitos humanos de muita gente, mas são invisíveis até mesmo no discurso global sobre direitos humanos. Consideremos a Declaração do Milênio da ONU, adotada em 2000, como marco político global para o desenvolvimento, que menciona a discriminação apenas duas vezes. Essas referências dizem respeito à violência contra as mulheres e à implementação da Convenção sobre a Eliminação de Todas as Formas de Discriminação contra as Mulheres. Mais recentemente, a Assembleia Geral aprovou por consenso um programa completo de ação para a Década Internacional dos Afrodescendentes (2015-2024), que visa fortalecer a promoção, a proteção e o cumprimento dos direitos dos afrodescendentes. No entanto, a implementação da Década permanece lenta, pois o número de países que adotaram formalmente um programa de ação relacionado continua limitado. Nenhum fórum foi criado até agora para consultar pessoas de ascendência africana, conforme exigido pela resolução da Assembleia Geral que inaugurou a Década (ACHIUME, 2018, p. 143).
\end{abstract}

A não efetivação de ações na década internacional dos afrodescendentes revela o silenciamento e a morosidade na agenda dos direitos humanos quando se trata de justiça racial. Ainda para a autora, é necessário "olhar para o fundo" e sair do debate raso dessa problemática. Compreender as raízes dessa incapacidade coletiva ou negligência calculada dentro do movimento e sistema global de direitos humanos exige uma reflexão profunda e mudanças centrais na forma de produzir conhecimento e garantir espaços de tomadas de decisão para aqueles que sofrem nas linhas de frente da discriminação, subordinação e exclusão raciais.

Um sistema formado por ONGs globais de Direitos Humanos que negligenciam a pauta das desigualdades e subordinações raciais é mortal para as populações discriminadas. É necessário que as perspectivas das pessoas discriminadas por questões étnicas e raciais e que as enfrentam cotidianamente tenham maior inclusão e representação dentro do sistema e da agenda global de direitos humanos (ACHIUME, 2018).

É fundamental, mais do que nunca, empregar uma perspectiva de justiça racial. Como bem colocam Berbec-Rostas et al. (2018, p. 110), “essa compreensão nos permitirá fazer intervenções mais minuciosas e impactantes que possam abordar as dimensões políticas e econômicas das violações de direitos humanos".

\title{
Vidas descartáveis e resistências cotidianas
}

Edificar estruturas que aproximem as realidades sociais de brancos e não brancos é um desafio enorme que demanda uma engenharia política, jurídica e econômica fora dos paradigmas adotados até então. Nas últimas décadas, políticas públicas de objetivos diversos, adotadas em diferentes níveis de governo, têm buscado assegurar as bases para a igualdade formal no País. Por sua vez, os indicadores socioeconômicos de variada natureza demonstram avanços nas condições de vida das populações, bem como no acesso a serviços e direitos. Contudo, o abismo racial ainda é profundo.

A nós neste estudo interessa especialmente compreender a realidade dos povos originários e povos e comunidades tradicionais. A Convenção 169 da Organização Internacional do Trabalho (OIT), ratificada em 1989, que trata dos direitos dos povos indígenas e tribais no mundo, e o Decreto 6040/2007, que institui a Política Nacional de Desenvolvimento Sustentável dos Povos e Comunidades Tradicionais, proporcionaram avanços no direcionamento de políticas públicas a esses.

No Brasil, também foi um avanço a criação do Conselho Nacional de Povos e Comunidades Tradicionais $\left(\right.$ CNPCT) ${ }^{3}$ pelo Decreto $n^{\circ} 8.750$, de 9 de maio de 2016, órgão colegiado de caráter consultivo que tem por principal objetivo promover o desenvolvimento sustentável dos povos e comunidades tradicionais, com vistas a reconhecer, fortalecer e garantir seus direitos, inclusive os de natureza territorial, socioambiental, econômica, cultural, seus usos, costumes, conhecimentos tradicionais, ancestrais, saberes e fazeres, suas formas de organização e suas instituições.

Para o Ministério da Mulher, da Família e dos Direitos Humanos (MDH) (2018)4 , os PCTs são compostos pelos seguintes segmentos: povos indígenas; comunidades quilombolas; povos e comunidades de terreiro/povos 
e comunidades de matriz africana; povos ciganos; pescadores artesanais; extrativistas; extrativistas costeiros marinhos; caiçaras; faxinalenses; benzedeiros; ilhéus; raizeiros; geraizeiros; caatingueiro; vazanteiros; veredeiros; apanhadores de flores sempre vivas; pantaneiros; morroquianos; povo pomerano; catadores de mangaba; quebradeiras de coco babaçu; retireiros do Araguaia; comunidades de fundos e fechos de pasto; ribeirinhos; cipozeiros; andirobeiros; caboclos; e juventude de povos e comunidades tradicionais.

Por meio desse importante espaço de controle social das políticas públicas ligadas às questões socioambientais, econômicas e culturais, hoje fortemente ameaçado ${ }^{5}$, os povos e comunidades tradicionais reivindicam o protagonismo de sua história, lutam a favor da vida com respeito às tradições, ao meio ambiente e ao Bem Viver e denunciam que seu modo de vida sustentável está ameaçado pela expansão do agronegócio.

Além de compartilharem da importância para a preservação ambiental e biodiversidade, e da herança cultural, social, ancestral de matriz africana e indígena deste País, os povos indígenas e as comunidades quilombolas têm em comum um passado histórico de expropriação e espoliação vivenciado desde o período de colonização. As relações capitalistas aqui estabelecidas e o racismo estrutural impuseram a esses segmentos participação social de forma subalternizada.

Os povos originários (indígenas) e tradicionais (quilombolas) têm sofrido severos ataques, desprezo e silenciamentos na atual conjuntura. Seus direitos têm sido negados e desmantelados, e as exigências legais de consulta livre, prévia e informações sobre medidas que possam afetar-lhes têm sido desrespeitadas, trazendo impactos no seu território, meio ambiente e modo de vida.

Determinados empreendimentos - cuja narrativa ancora-se no projeto neoliberal de desenvolvimento econômico do País - como a Hidrelétrica de Belo Monte/PA, Base de Lançamento de Alcântara ${ }^{6} / \mathrm{MA} \mathrm{e}^{2}$ diversos complexos portuários removeram centenas de famílias dos seus territórios sem a devida reparação ou plano de mitigação pelos danos advindos dessas obras, com sérios impactos socioambientais.

As narrativas que têm se proliferado são perpassadas de ódio e violência, posto que se baseiam na falsa ideia de que os povos originários e tradicionais representam entraves ao desenvolvimento e fazem uso de práticas que ferem os princípios constitucionais e promovem interferências em processos legislativos.

As comunidades quilombolas no Brasil totalizam, de acordo com dados atualizados da Fundação Cultural Palmares (2019), 3.386 comunidades existentes e 2.744 certificadas. No Ceará há 49 certificadas. A maior quantidade de comunidades permanentes de quilombos reconhecidos encontra-se no Nordeste (2.138), seguida da região Sudeste (527), Norte (366), Sul (191) e Centro-Oeste (164).

Os povos indígenas do Ceará são: Anacé, Gavião, Jenipapo-Kanindé, Kalabaça, Kanindé, Kariri, Pitaguary, Potyguara, Tabajara, Tapeba, Tapuya-Kariri, Tremembé, Tubiba Tapuya e Tupinambá. Essas 14 (quatorze) etnias totalizam aproximadamente uma população de 33 mil indígenas, presentes em 20 (vinte) municípios cearenses. Apenas uma terra indígena está totalmente regularizada pelo Estado brasileiro; quatro terras estão demarcadas e as demais se encontram em etapas inseridas nas terras da Funai.

Pesquisas têm elucidado que esses povos apresentam inúmeros problemas relacionados prioritariamente aos processos de demarcação e titulação de suas terras, conflitos territoriais, ataques às suas formas de organização política e dificuldade em acessar políticas públicas. Convivem com violação de direitos no tocante à questão da terra, à segurança, à educação e à saúde diferenciadas.

Esses grupos étnicos estão posicionados socialmente como representativos da zona do não ser, são racialmente subalternizados. No que se refere à atual situação da demarcação de seus territórios, essa é perpassada de conflitos, ataques frequentes por parte dos donos dos grandes empreendimentos, criminalização das lideranças, comprometimento na base organizativa.

De acordo com o Relatório sobre os Direitos dos Povos e Comunidades Tradicionais elaborado pelo Conselho Nacional de Direitos Humanos em 2018, as violações de direitos humanos sofridas pelos povos e comunidades tradicionais são inúmeras e estão permeadas pelo questionamento à sua tradicionalidade e à sua autodeterminação como povo tradicional. A desterritorialização dos povos e comunidades tradicionais é uma violação praticada desde a colonização. Em várias situações, os povos e comunidades tradicionais têm as condições objetivas de regularização das suas terras negadas e ficam mais vulneráveis à expropriação e à grilagem, e essas por sua vez acontecem de forma violenta por mecanismos privados, como milícias ou pelo próprio Estado.

Outra violação que afeta muitos povos e comunidades tradicionais é a supressão e retirada dos bens da natureza, bens essenciais para sua sobrevivência e com os quais estabelecem uma relação de interdependência. A expansão do agronegócio monocultor também tem sido um elemento forte de destruição dos seus territórios, por meio da utilização de agrotóxicos que contaminam o solo e a água da região, e por ações estatais ou privadas que restringem ou impedem a manutenção do modo de vida tradicional dos povos e comunidades tradicionais, como é o caso da instalação de empreendimentos turísticos, de infraestrutura, com a instalação de rodovia, linhas de transmissão, hidrelétricas, da exploração mineral etc. 
A proteção ao seu povo e ao seu território leva muitas lideranças dos povos e comunidades tradicionais e instituições a sofrerem processo de criminalização, junto ao crescimento das milícias armadas, dentro de um contexto de legitimação do discurso de ódio contra esses povos e comunidades e, a rigor, contra a diversidade em suas mais diferentes expressões. A ascensão das forças de extrema direita no Brasil e no mundo, fomentado por uma rede de notícias falsas (Fake News), vem colocando por terra a tese da cordialidade do povo brasileiro, corroborada pelo fato de ser um país com os maiores índices de assassinato da população negra, pessoas LGBT, ambientalistas e jornalistas no mundo. E que pode aumentar, com o risco da flexibilização do uso de armas. A "oficialização" do discurso de ódio por meio das mídias sociais ou no cotidiano, como forma de expressão do pensamento que desqualifica, humilha e inferioriza indivíduos e grupos sociais, tem o objetivo de propagar a discriminação desrespeitosa para com todo aquele que possa ser considerado "diferente", quer seja por sua etnia, sua opção sexual, sua condição econômica ou seu gênero, para promover a sua exclusão social e desvalorização (CONSELHO NACIONAL DE DIREITOS HUMANOS, 2018, p. 59).

Esses constituem casos graves de violação de direitos humanos, demonstrando o quanto se tem de desafios para garantir o reconhecimento étnico, justiça racial e respeito pelo modelo de desenvolvimento pautado no bem viver que apresentam como povos originários e tradicionais.

Contudo, esses grupos populacionais têm apresentado, ao logo dos séculos, formas plurais de resistências, e até hoje nos ensinam cotidianamente sobre o viver, o produzir e o resistir, onde se destacam: suas formas próprias de se organizar e fazer a gestão de seus territórios; a reorganização da educação escolar indígena; organização das mulheres indígenas com maior sistematização de suas demandas, luta contra a violência contra as mulheres, visibilidade das pajés, caciques, professoras, agentes de saúde, curandeiras etc.

Os indígenas no Ceará encontram formas próprias de se organizar e fazer a gestão dos seus territórios. Para tanto, organizaram suas demarcações próprias, chamadas de retomadas. As quatro terras indígenas demarcadas hoje - Tapeba, Pitaguary, Jenipapo Kanindé e Tremembé - passaram por esse processo de autodemarcação. Dessa forma, os indígenas garantem seu território tradicional e pressionam o poder público a manter o que está disposto nos artigos 231 e 232 da Constituição Federal. [...] Não podemos esmorecer e nem temos o direito de fraquejar. Que todos os encantados nos protejam nessa árdua missão de defesa dos direitos dos povos indígenas (Ceiça Pitaguary - Coordenadora da Federação dos Povos Indígenas do Ceará, 2018).

Nessa mesma linha de pensamento, para Gomes (2015) "a história dos quilombos, do passado e do presente, se transformou em bandeira de luta". Isso significa dizer que o movimento quilombola passou por ressignificações ao longo do tempo, e, atualmente, reivindicam-se como sujeitos de direitos.

Em 2019, a entidade de representação do movimento quilombola cearense realizou, através de orçamento público da Secretaria de Desenvolvimento Agrário, um mapeamento das comunidades quilombolas do Ceará, com sua equipe total composta de pesquisadores quilombolas. O mapeamento teve a intenção de mapear todos os quilombos existentes no estado, mesmo aqueles que não fossem ainda reconhecidos pela Fundação Cultural Palmares, além de constatar as demandas sociais, econômicas e políticas dessas comunidades. Segundo o documento, existem atualmente, no Ceará, 87 comunidades quilombolas - dentre estas, 49 certificadas pela FCP.

Um dos resultados do mapeamento aponta para as maiores problemáticas dos quilombos cearenses, que são: a invisibilização do negro, sobretudo quilombola; carência de políticas universais e específicas; ausência de equipamentos públicos de saúde e educação; latifúndio; dificuldade de acesso à Declaração de Aptidão do Programa Nacional de Fortalecimento da Agricultura Familiar (Pronaf) - programa este que abre portas para o acesso a outras políticas públicas; falta de água potável na maioria dos territórios; empregabilidade e renda; infraestrutura de estradas e projetos sociais para todos os grupos geracionais, sobretudo para a juventude.

No Ceará, nós não temos nenhum quilombo titulado, o que significa dizer que a justiça racial para esse povo segue em um horizonte distante. Mesmo assim, no estado temos algumas comunidades que estão perto de conseguir os títulos definitivos de seus territórios. São elas: Sítio Arruda no município de Araripe, as Comunidades de Encantados do Bom Jardim, Brutos e Lagoa das Pedras no município de Tamboril, Alto Alegre no município de Horizonte, Comunidade de Base em Pacajus, Três Irmãos em Croatá, Serra dos Chagas em Salitre, e no município de Novo Oriente a comunidade quilombola Minador. 


\section{Considerações finais}

É inegável que as condições de vida desses povos são marcadas por vulnerabilidades, sendo um dos maiores desafios a demarcação de seus territórios e os conflitos com os grandes proprietários de terra. Esses grupos, discriminados por sua ancestralidade e condição étnica, convivem cotidianamente com a violação do direito originário, morosidade na demarcação das terras, conflitos fundiários, destruição do ambiente necessário à sua reprodução física e cultural (LIMA, 2018, p. 26-27).

Acresce o avanço do autoritarismo e de legislações anti-indígena, retrocessos nos marcos legais que tomam grandes contornos na sociedade na atual conjuntura, negação dos direitos previdenciários dos indígenas agricultores, artesãos, pescadores e o direito a aposentadoria especial. O racismo estrutural alcança ainda as agendas das políticas públicas e dos direitos humanos, produzindo uma abordagem rasa que não desloca estruturas de forma a promover uma real alteração nas condições de subalternização e exploração na sociedade capitalista.

Prevalecem a invisibilização dessa questão, que é estruturante das relações sociais, e a insipiência das iniciativas, somando-se ao ataque sistemático às conquistas históricas. Essa condição possibilita a continuidade do genocídio dessas populações, em curso desde o período colonial.

As reflexões aqui utilizadas nos levam a considerar que o Poder Público precisa assumir sua responsabilidade no enfrentamento das condições materiais e simbólicas que subsidiam vulnerabilidades desses povos. É tarefa no tempo presente desconstruir estruturas que contribuem para uma série de violação de direitos, ao mesmo tempo em que precisaremos compreender como as estruturas opressivas se sobrepõem.

Também é salutar o enfrentamento ao racismo institucional, que age no corpo das instituições públicas e privadas e inclusive invisibiliza a necessidade de iniciativas governamentais voltadas ao combate ao racismo e superação das desigualdades - "a percepção ainda fortemente presente nas organizações de que a temática racial é suplementar e mesmo acessória faz com que a efetivação dessas políticas seja uma tarefa árdua e penosa" (THEODORO, 2013, p. 9). Outro aspecto suscitado pelo autor se refere ao dimensionamento dos programas e ações, tendo em vista a grandeza da problemática racial no Brasil - as ações e programas de Promoção da Igualdade Racial devem ser profundos e contínuos, com direta interferência nas relações de poder e enfrentamento ao racismo.

A todos nós incluídos em espaços de promoção e defesa dos direitos humanos impõe-se o desafio de pautar ações voltadas ao desmantelamento do racismo estrutural responsável pelos altos padrões de desigualdades e desequilíbrio de poder; promover direitos e responsabilizar violadores; colocar o racismo institucional em xeque; assegurar uma convivência intercultural para a construção de uma realidade livre e concretamente democrática, assim como desenvolver um diálogo aberto e franco sobre diversidade racial e representatividade nos espaços de poder e decisão.

\section{Referências}

ACHIUME, E. Tendayi. Pautando a Igualdade Racial na Agenda Global de Direitos Humanos. Revista Internacional de Direitos Humanos (SUR), v. 15, n. 28, p. 141-150, 2018.

ALMEIDA, S. L. de. O que é racismo estrutural? Belo Horizonte: Letramento, 2018.

BERBEC-ROSTAS. M. et al. A questão racial importa. Revista Internacional de Direitos Humanos (SUR), v. 15, n. 28, p. 141-150, 2018.

BRASIL. Decreto $n^{\circ}$ 6.040, de 7 de fevereiro de 2007. Institui a Política Nacional de Desenvolvimento Sustentável dos Povos e Comunidades Tradicionais. Disponível em: http://www.planalto.gov.br/ccivil_03/_ato2007-2010/2007/decreto/d6040.htm. Acesso em: 2 out. 2017.

GOMES, F. dos S. Mocambos e quilombos: uma história do campesinato negro no Brasil. São Paulo: Claro Enigma, 2015.

JACCOUD, L. O combate ao racismo e à desigualdade: o desafio das Políticas Públicas de promoção da igualdade racial. In: THEODORO, M. (org.). As políticas públicas e a desigualdade racial no Brasil: 120 anos após a abolição. Brasília: Ipea, 2008. p. 131-166.

LIMA, R. de Q. Violação do Direito Indígena à terra no Ceará pós-constituição de 1988. In: Associação para Desenvolvimento Local CoProduzido (org.). Violação de Direitos Indígenas no Ceará: terra, educação, previdência, mulheres. Fortaleza: Expressão, 2018.

PIRES, T. Racializando o debate sobre Direitos Humanos: limites e possibilidades da criminalização do racismo no Brasil. Revista Internacional de Direitos Humanos (SUR), v. 15, n. 28, p. 65-75, 2018.

SCHWARCZ, L. M. Sobre o autoritarismo brasileiro. São Paulo: Companhia das Letras, 2019.

SCHWARCZ, L. M.; STARLING, H. M. Brasil: uma biografia. São Paulo: Companhia das Letras, 2018.

THEODORO, M. As relações raciais, o racismo e as políticas públicas. In: ENCONTRO NACIONAL DAASSOCIAÇÃO NACIONAL DE PÓS-GRADUAÇÃO E PESQUISA EM CIÊNCIAS SOCIAIS, 37, São Paulo. Anais [...] São Paulo: Anpoc, 2013. Disponível em: https://anpocs.com/index.php/papers-37-encontro/mr-2/mr10/8786-as-relacoes-raciais-o-racismo-e-as-politicas-publicas/file. Acesso em: 28 out. 2019. 


\section{Notas}

1 A definição jurídica do termo "povos e comunidades tradicionais" busca contemplar a diversidade étnica da população nacional, dispondo que se trata de "grupos culturalmente diferenciados e que se reconhecem como tais, que possuem formas próprias de organização social, que ocupam e usam territórios e recursos naturais como condição para sua reprodução cultural, social, religiosa, ancestral e econômica, utilizando conhecimentos, inovações e práticas gerados e transmitidos pela tradição", segundo o inciso I do art. $3^{\circ}$ do Decreto Federal n ${ }^{\circ} 6.040$, de 2007, que institui a Política Nacional de Desenvolvimento Sustentável dos Povos e Comunidades Tradicionais (PNPCT). Já o inciso II do mesmo dispositivo define territórios tradicionais como "os espaços necessários à reprodução cultural, social e econômica dos povos e comunidades tradicionais, sejam eles utilizados de forma permanente ou temporária".

2 Lei n 12.288, de 20 de julho de 2010-Institui o Estatuto da Igualdade Racial; altera as Leis nº 7.716, de 5 de janeiro de 1989, 9.029, de 13 de abril de 1995, 7.347, de 24 de julho de 1985, e 10.778, de 24 de novembro de 2003.

3 O decreto que cria o Conselho Nacional de Povos e Comunidades Tradicionais foi alterado pelo Decreto ${ }^{\circ} 9.465$ de 9 de agosto de 2018, órgão colegiado de caráter consultivo, antes integrante da estrutura do Ministério dos Direitos Humanos e hoje parte da estrutura do Ministério da Mulher, da Família e dos Direitos Humanos (MMFDH).

4 Segundo informações do Conselho Nacional de Povos e Comunidades Tradicionais, existem 84 segmentos de PCTs. Porém, quando foi criado tinha 28 membros e agora com sua recriação conta com 22 membros. Disponível em: https://www.mdh.gov.br/todas-as-noticias/2018/agosto/ mdh-incorpora-por-meio-de-decreto-o-conselho-nacional-dos-povos-e-comunidades-tradicionais.

5 OConselho Nacional de Povos e Comunidades Tradicionais, os segmentos da sociedade civil, diante da ameaça do Decreto ${ }^{\circ} 9.759$ de 11 de abril de 2019, que extingue e estabelece diretrizes, regras e limitações para colegiados da administração pública federal, cobrou medidas e apresentou uma manifestação sobre a recriação desse conselho a serem adotadas pelo Governo Federal.

6 Expansão da base espacial de lançamento de Alcântara no Maranhão fará a remoção de 350 famílias quilombolas, e serão expulsas à força 792.

Daiane de Oliveira Gomes

daianedaine@ hotmail.com

Mestre em Serviço Social pela Universidade Estadual do Ceará (UECE)

Assistente Social do Instituto Federal de Educação, Ciência e Tecnologia da Paraíba (IFPB)

\section{IFPB Campus Cajazeiras}

Rua José Leôncio da Silva, 300 - Jardim Oasis

Cajazeiras - Paraíba - Brasil

CEP: 58900-000

\section{Maria Zelma de Araújo Madeira}

zelmadeira@yahoo.com.br

Doutorado em Sociologia pela Universidade Federal do Ceará (UFC)

Professora do Programa de Pós-graduação em Serviço Social, Trabalho e Questão social da Universidade Estadual do Ceará (UECE)

\section{UECE}

Av. Dr. Silas Munguba, 1700 - Itaperi

Fortaleza - CE

CEP: 60714-903

\section{Wanessa Nhayara Maria Pereira Brandão}

brandao.wanessa@gmail.com

Graduada em Serviço Social pela Faculdade Metropolitana da Grande Fortaleza

Mestranda do Programa de Pós-graduação em Serviço Social, Trabalho e Questão social da Universidade Estadual do Ceará (UEC)

\section{UECE}

Av. Dr. Silas Munguba, 1700 - Itaperi 
Fortaleza - CE

CEP: 60714-903

\section{Agradecimentos}

Não se aplica.

\section{Agência financiadora}

Não se aplica.

Contribuições das autoras

$\mathrm{O}$ artigo foi construído coletivamente com contribuições das três autoras em todas as suas partes.
Aprovação por Comitê de Ética e consentimento para participação

Não se aplica.

Consentimento para publicação

Consentimento das autores.

Conflito de interesses

Não há conflito de interesses. 